\title{
A PSYCHOLOGICAL INQUIRY INTO THE NATURE OF THE CONDITION KNOWN AS CONGENITAL WORD- BLINDNESS.
}

\author{
BY LUCY G. FILDES.
}

THE aim of the investigation about to be described was to discover something of the psychological characteristics of the condition commonly called by the misleading term of congenital word-blindness-a condition which shows itself most clearly in the subjects' extremie difficulty, or even total failure, in learning to read, and appears to be closely related to the various forms of acquired alexia met with commonly as the result of brain injury in later life.

Three explanatory theories, it will be remembered, have been put forward as indicating the nature and cause of this condition, viz. :-

(1) A theory which assumes the existence of definitely localized and circumscribed visual and auditory word-centres in the brain, the destruction or isolation of which will destroy language in either its visual or its auditory aspect;

(2) A theory which interprets word-blindness as only one symptom in a general lowering of mental ability; and

(3) One which attributes the condition to a more specialized lowering of power in the primary visual centres, rendering true visual perception of words and of other complex sense-data difficult.

The main problems raised by these different interpretations are two in number. Is inability to learn to read or the loss of the power of reading dne to specific or to general defect? If the former, does the defect show itself only in reading, or does there appear to be any general lowering of visual power? A psychological investigation should throw light on these points.

. The subjects mainly used for the investigation were twenty-six in number-all children between the ages of 9 and 16 years, who were in attendance either at ordinary elementary schools (4) or at special schools for mentally defective children (22). They were selected on the report of their teachers as finding reading a very great difficulty. Before the work peculiar to the investigation was begun, all the children were tested $(x)$ with the Stanford revision of the Binet scale, in order to get 
some idea of their general mental capacity, and (b) with various recognized reading tests, in order to get an estimate of their reading power.

The resalts of these tests show that the subjects differed very considerably in general ability as measured by the Terman scale-the intelligence quotients varying from 50 to 111 . Classification on the basis of these results gives the following groups :-

$\begin{array}{rllll}1 \text { subject has superior intelligence } & \ldots & \ldots & \ldots & \text { I.Q. }=111 \\ 4 \text { subjects belong to the class dull and backward } & \ldots & \ldots & \text { I.Q. }=82-88 \\ 8 \text { subjects show border-line deficiency } & \ldots & \ldots & \ldots & \text { I.Q. }=70-79 \\ 19 \text { subjects are classifiable as morons of different grades } & \ldots & \text { I.Q. }=50-69\end{array}$

Fonr of the subjects from the first two groups were in normal schools, the fifth in a school for the mentally defective. It is interesting to note that this boy fell below the others of the same group, chiefly in reading ability. He was, however, better at reading than the brightest boy, who showed superior intelligence.

Testing for reading power in particular revealed also a great variation in the ability of the subjects. Some of them could recognize no single letter, word or figure with any certainty; others could read simple words and knew all letters and figures well. It was estimated, however, that no child was less than four years retarded in reading ability and some of them showed retardation much greater than this. Even the children who could read best had marked difficulty in writing from memory words which they could read-they could not spell.

No relationship existed between the subjects' intelligence quotients and their power in reading. Two of the worst readers were the least intelligent and most intelligent boys. The three worst cases examined, i.e., cases with no reading power at all, had intelligience quotients of 61, 79 and 78 respectively. Many defective boys with such high intelligence quotients read quite well.

The tests in the scale used for finding the intelligence quotients gave no indication of any special disability common among the children. On the whole they failed most on tests requiring auditory repetition, bat this characteristic does not mark them off from defective children who can read.

The main suggestion of the preliminary work, then, is that inability to learn to read depends rather on a specific than on a general defect, although in school life such a defect may, because of its nature, simulate one more wide-spreading in character. 


\section{EXPERIMENTAL WORK.}

The experiments aimed at investigating each subject's ability in the various forms of mental activity known to be involved in the complex act of reading, in so far as that act implies the power to recognize words, letters and figures previously taught. Reading proper, i.e., reading new words, involves, of course, yet farther powers, in particular the power of ready analysis and synthesis and quickness in applying what is known to new situations; and for this reason probably most defective children are slow in reading and in learning to read. It was, however, in their failure to retain what had actually been taught that our group of non-readers showed their extreme peculiarity, and because of this fact the experiments aimed primarily at testing activities required here. These activities fall into three groups :-

(1) Rapid and easy visual discrimination of forms, together with the sbility to retain these without undue repetition.

In particular this discrimination must be extended to forms which closely resemble each other (e.g.; ran, ram), and also to those which differ only in the arrangement of their parts, (e.g., b, d, p-god, dog-saw, was-\&c.). It may here be noticed in passing that this power of retaining the knowledge of the relationship of the parts to each other and to the whole in a visual percept is one often late in development.

(2) A similar rapid and easy discrimination of sounds.

(3) The possibility of establishing readily an association between a given form and a given sound.

Hence the experiments used can also be arranged in three groups according to the special power which they aimed at testing. Each was carried out with most of the members of the non-reading group, although it was not always possible to include them all. In each experiment the results of the group of non-readers tested are compared with those of a group of readers, equated as far as possible with the non-readers with regard to age and mental ability.

All the experimental work was carried out individually with each child, the procedare being the same throughout the experiment in all cases.

\section{\$1.-Experiments to test the Powers of Visual Discrimination and Retention.}

Experiment 1.-The aim of this experiment was to test the subject's ability to distinguish between unlike and to recognize like forms when these are presented in sequence. In particular it was planned to reveal whether and how far- 
(1) Forms showing right and left or top and bottom reversal can be distinguished in memory, and

(2) Forms containing common elements tend to be confused.

Eighteen series of forms were prepared, each series containing some quite different and some similar or like forms. The number of forms in each series was twenty; of these eight were either exactly like or closely resembled others. The same form was never used in more than one series. Each series was taken as a separate unit and the subjects were told that they were to make their judgments in relation. to the forms of that series only.

The forms were shown to the snbjects individually, each being exposed for a period of two seconds. After each exposure the subject was required to say "Yes" if he judged the form to be like one already seen in the series, and "No" if he judged it to be a different form.

Care was taken to prevent the repeated forms from occupying similar positions in the different series. As a rule, two series of forms only were exposed during one sitting with each subject. In this way, the possibility. of confusion with forms of other series was reduced; as a matter of fact there is no evidence to show that such confusion constituted a source of error.

The following are examples of the forms used :-

Series 1.- Repetition of like forms. ( ${ }^{\circ}$ Indicates that the form is a repeated one.)

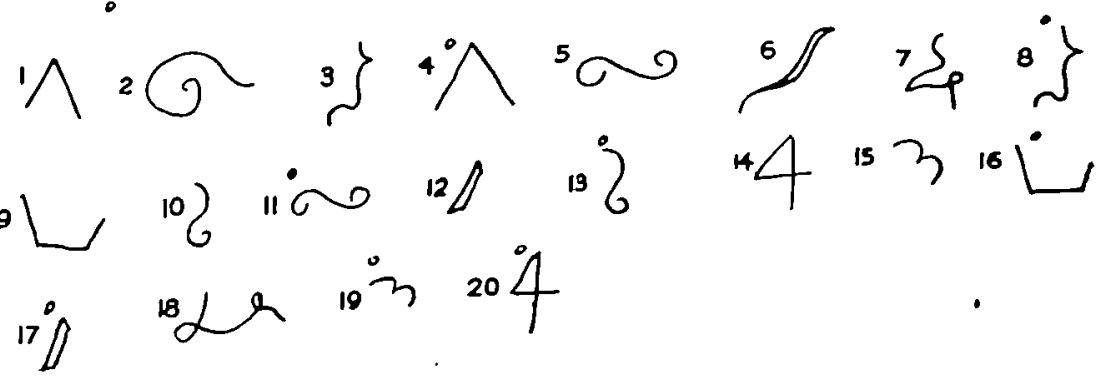

Series 3.-Repetition of forms inverted.
15
$\sqrt[2]{ }$
$3)$
$4 \varepsilon$
$5 j$
$\alpha$
$7 / 1$
$\sqrt{0}$
93
$10 V^{\circ}$
$" f$

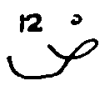
13

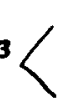
$4 l^{\circ}$
$\stackrel{15}{\longrightarrow} \mathbb{l}^{\circ}$
$17 \lesseqgtr$
${ }^{18}$

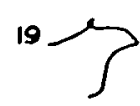
$20 \longleftrightarrow 0$ 
The repeated forms in the different series were :-

Series 1 and 2 . Exactly alike.

Series 3 and 4. Alike except for RL inversion.

Series 5 and 6 . Alike except for TB inversion.

(After prssing judgment on the foregoing series, the subjects were told that the differences in direction were to count as points of dissimilarity.)

Series 7 and 8. Alike except for TB inversion.

Series 9 and 10. Alike except for RL inversion.

Series 11, 12 and 13. Alike except for either TB or RL inversion.

Series 14, 15 and 16 . Alike either wholly or partially.

Series 17 and 18. Alike either wholly or in one part-the whole form consisting of three parts.

The results, given in percentages, are tabulated below. Fourteen non-reading boys worked through the whole eighteen series. Twenty-four non-reading boys and seven reading boys (i.e., boys who could read up to or beyond their intelligence level), also defective, worked with the first two series also.

Table I.-Showing the Ability of Non-Readisg Boys to recoghize Like Fonas ab LiKe, AND DIFFrReNT ForMs as DIFFerewt.

\begin{tabular}{|c|c|c|c|c|}
\hline $\begin{array}{l}\text { No. of } \\
\text { series }\end{array}$ & & $\begin{array}{l}\text { Porcentage of answers "Yes" } \\
\text { to fornis entirely alike or } \\
\text { alike in some particular }\end{array}$ & & $\begin{array}{l}\text { Percentage of answers } \\
\text { "Yes" to forms } \\
\text { ontirely different }\end{array}$ \\
\hline 1 & $\ldots$ & $82 \cdot 5$ & .. & $5 \cdot 5$ \\
\hline 2 & . & $65 \cdot 8$ & .. & $2 \cdot 7$ \\
\hline 3 & .. & $66 \cdot 6$ & $\cdots$ & $1 \cdot 6$ \\
\hline 4 & $\ldots$ & $56 \cdot 6$ & .. & $5 \cdot 0$ \\
\hline 5 & $\cdots$ & $60 \cdot 7$ & $\ldots$ & $5 \cdot 3$ \\
\hline 6 & $\ldots$ & $59 \cdot 8$ & $\because$ & $5 \cdot 3$ \\
\hline 7 & $\ldots$ & $47 \cdot 9$ & .. & $6 \cdot 5$ \\
\hline 8 & .. & $48 \cdot 2$ & $\ldots$ & $2 \cdot 4$ \\
\hline 9 & $\ldots$ & $50 \cdot 0$ & . & $2 \cdot 9$ \\
\hline 10 & $\cdots$ & $45 \cdot 0$ & $\cdots$ & $6 \cdot 5$ \\
\hline 11 & $\cdots$ & 428 & $\ldots$ & 4.8 \\
\hline 12 & $\ldots$ & $46 \cdot 5$ & .. & $6 \cdot 5$ \\
\hline 19 & $\ldots$ & 557 & $\ldots$ & 7.0 \\
\hline 14 & .. & +692 and $^{\circ} 13.4$ & . & $6 \cdot 4$ \\
\hline 15 & .. & +51.9 and ${ }^{\circ} 28.0$ & .. & $7 \cdot 7$ \\
\hline 16 & $\cdots$ & +32.7 and ${ }^{\circ} 26.9$ & . & $4 \cdot 4$ \\
\hline 17 & .. & +38.0 and ${ }^{\circ} 15 \cdot 0$ & .. & $13 \cdot 9$ \\
\hline 18 & .. & $+51.9 \mathrm{and}^{\circ} 25 \cdot 0$ & .. & $5 \cdot 1$ \\
\hline
\end{tabular}


Table II.-Showho Comparative Ability of Readebs and Non-readers in ReCognizing Likefess in Forms successively presented.

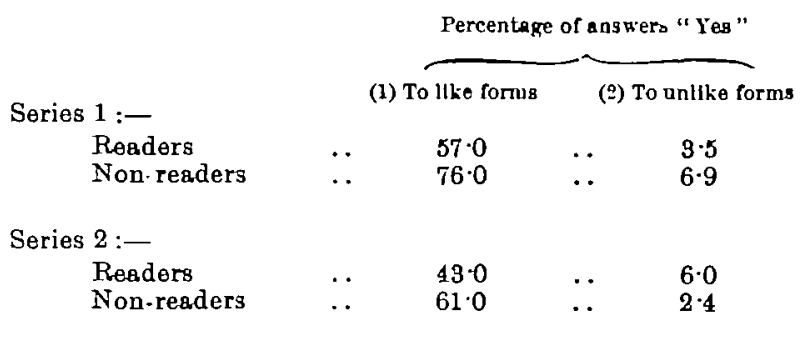

These results seem to warrant the following inferences - -

(1) All the children examined were able with considerable ease to recognize like and to distinguish unlike forms successively presented, when the forms were like or unlike in all particalars. The non-readers were in no way inferior here to the readers.

(2) The non-readers found forms alike except for differences of orientation very difficult to distinguish, even when special attention was directed to that aspect of the form.

(3) Difficulty was also occasioned by repetition of a part of a form in other surroundings.

It was unfortunate that the other series could not be worked through with the reading group. Reference to a similar experiment, however, performed with a group of younger subjects, suggests that the difficulty shown here by the non-readers in dealing with forms differently orientated is considerably in excess of the normal. The results of this younger group show only 26.4 per cent. and 23.7 per cent. of error in dealing with two like series.

Experiment 2.-This experiment was planned to discover whether the length of exposure of a form made any difference to the children's power to recognize it on a second presentation, and if this did occur to see whether the non-readers in particular suffered from shortening of the exposure.

The subjects were fifteen non-readers and ten readers.

The work was similar to that of Experiment 1, a series resembling in construction Series 1 and 2 of that experiment being used. It differed only in that here, by the use of a simple drop-shutter apparatus, the exposure-tinie of each form was momentary, instead of being, as in the first experiment, two seconds in length. 
Table III. - Showigg Couparative ability of Readerg and Non-readerb in recogrizino Like Forms oxder Conditiong of Monentapy Exposurg.

\begin{tabular}{|c|c|c|c|c|}
\hline \multirow[b]{3}{*}{ Readers } & & \multicolumn{3}{|c|}{ Percentage of } \\
\hline & \multicolumn{2}{|c|}{ (1) Correct enswirs } & \multicolumn{2}{|c|}{ (2) Incorrect answers } \\
\hline & $\cdots$ & $45 \cdot 0$ & . & $19 \cdot 0$ \\
\hline Non-readers & $\ldots$ & 56.0 & $\cdots$ & $10 \cdot 0$ \\
\hline
\end{tabular}

There is no evidence here that non-readers as a class fail in speed of perception or in ability to recognize forms with material of this type.

Note.-In spite of previous practice with the apparatus all the children found this work much more difficult than the related work in Experiment 1, and it is not felt that the results are very trustworthy, since certain individuals, finding the work beyond their powers, tended to respond automatically-saying "Yes" or "No" to all the forms. Cases in which this tendency operated throughout have been omitted from the results.

Experiment 3. Reproduction of forms.-In order to test further the effect of length of exposure on the ability to perceive a form in the two selected groups of subjects, an experiment was planned which demanded the reproduction of forms seen only with momentary exposure.

The forms were exhibited by means of the apparatus already mentioned, each form being shown three times in succession. After each exposure the subject was required to draw what he had seen. Finally the subjects copied each of the drawings from the original card.

Twenty boys, ten readers and ten non-readers, performed this experiment.

It 18 in practice impossible to judge the results by any allocation of marks, but the general impression gained by a careful examination of the drawings is that there is nothing to distingaish the work of the non-reading group of boys from that of the readers. Some of both groups reproduce well and some reproduce badly. A mach higher correlation exists between the subjects' reproductions and their drawings from the copy than between their reproductions and their ability to read.

- We seem, then, justified in inferring that slowness in visual perception is not an important factor in causing difficulty in learning to read.

Experiment 4. An experiment in learning from visual material.The aim of this experiment was to discover whether the boys grouped as non-readers showed any special disability in learning from visual material, the method of learning being left free. 
To this end four large squares were prepared, each divided into nine small squares. Each small square was filled with either (1) a colour (all the subjects could name every colour used quite accurately); or (2) a simple geometrical drawing or a representation of some common object.

Each large square was shown to the subject for a fixed period (thirty seconds). He was then required to indicate on a daplicate skeleton square the contents of each small square.

This experiment was performed by thirty-six boys, twenty-four non-readers and twelve readers.

The filled-in duplicate squares were marked as follows:-

(1) Each form or colour correctly placed received one mark; (2) each form or colour correctly given but misplaced by not more than one square in any direction received half a mark.

The marks gained by the respective groups are given below :-

Table IV.-Kegulta of the Coloun Square Fixpeniment.

The figures given indicate the percentage of actual in relation to possible successes with each square, each group of boys being taken as a whole.

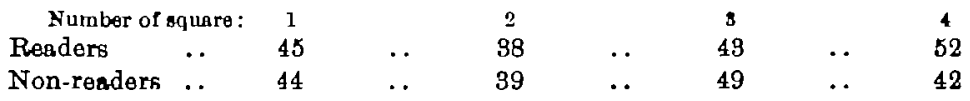

Examination of these results makes it quite clear that from this experiment no evidence can be obtained which would indicate that nonreaders find learning from visual any more difficult than do readers of equal mental attainments. The percentage of successes in the two groups are almost identical.

In all cases, however, the method of learning employed was auditomotor-visual.

Further, success in this experiment did not depend on the power. to differentiate between forms nearly alike or forms differing only in position. Results were considered as right if the drawings made were recognizable, irrespective of the accuracy of their details. Nearly 50 per cent. of the errors made were due to misplacement of the colours or forms, while many of the drawings showed faulty orientation.

Experiment 5.-In common with the two succeeding experiments, Experiment 5 aimed at carrying further the investigation already begun in Experiment 4, i.e., it was planned to discover whether the reading and non-reading groups differed in their ability to learn from visual material. These three experiments, however, differed from Experiment 4 in that- 
(1) The material used (digits and words) was actually of the kind ordinarily used in reading. Learning from it, therefore, demanded the power of discriminating rapidly between very similar visual presentations.

(2) The actual learning was more definitely visual in type. As far 8s possible auditory and motor aids to learning were prevented.

The fact that material such as digits and words could be used for experimental purposes with children defined as non-readers requires perhaps some explanation. The tests of reading ability were made at the beginning of the experimental work; these tests were made near its end, some nine months later. In the meantime attempts to teach reading had been carried out side by side with the actual experiments. No child had been found entirely incapable of learning any words or figures when tanght alone in this way. At the end of the nine months, therefore, all the subjects used for these three experiments could name all the words and figures employed in them quite well.

In Experiment 5 digits were used as learning material. A typed list of numbers was prepared, having on it four 3-place, four 4-place, and four 5-place numbers. These were exposed in turn to the subject, each for a period amounting to one second for each digit. Immediately after each exposure the subject was required to give the number seen.

The work was done by eleven readers and twenty-six non-readers. The results were marked in terms of error as follows:-

(a) Omission or insertion of a digit, or the substitution of one digit for another $=1$ error.

(b) Misplacement of a digit by not more than one place $=\frac{1}{2}$ error.

(c) Interchange of two neighbouring digits $=\frac{1}{2}$ error.

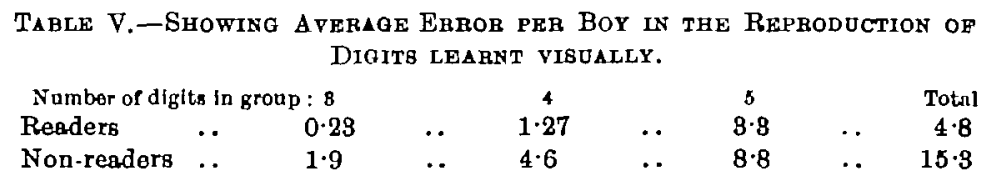

A glance at the table given above is sufficient to indicate the comparative failure of the non-reading group here. An examination of the nature of their errors is even more instructive. The chief causes of error were :-

(a) Misplacing of digits in the number given, and

(b) Misreading of digits similar in form, e.g., 6 and 9,5 and 8 , 5 and 3,3 and 8 , \&c.

The results of this experiment, therefore, seem to confirm those 
found in Experiment 1, viz., that non-readers as a class find difficulty in distinguishing between visual impressions which closely resemble each other, although they are readily able to appreciate and to retain more marked differences.

Experiment 6.-To test the power of reproducing numbers presented visually vith momentary exposure.

The main aim of this experiment has already been indicated (Experiment 5). Its further object was to test the effect of length of exposure on the reproduction of numbers.

The numbers used were printed on cards and exposed in the dropshutter apparatus previously mentioned. Five exposures of each number were made, the subject's reply after each presentation being noted. The numbers used were :-
(1) 71
(4) 65
(7) 27408
(3) 629
(5) 7980
(8) 049
(10) 914
(11) 36019
(13) 9502

Tabee VI.-Showing the Relative abicity of Reading and Non-reading Boys IN THE RRPRODUCTION OF NUMBERS EXPOSED MOMENTARILY.
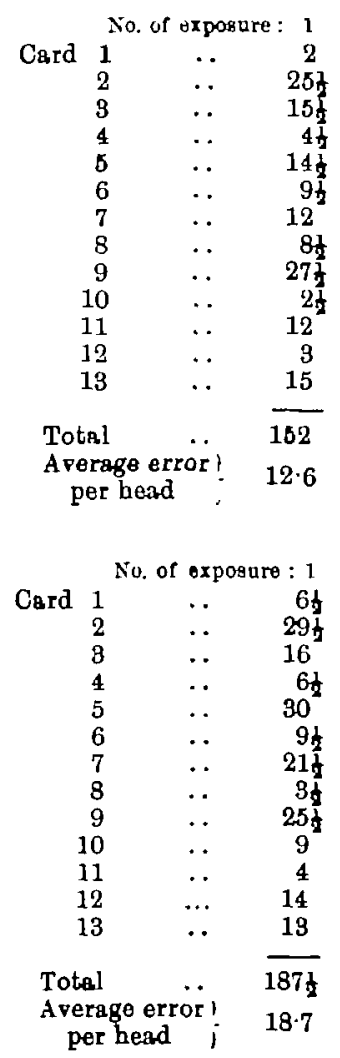
Group A.-Twelve Readers.

\begin{tabular}{|c|c|c|c|c|c|c|}
\hline 9 & & 3 & & 4 & & 5 \\
\hline$\cdots$ & . & 0 & . & 0 & $\ldots$ & 0 \\
\hline 17 & $\cdots$ & 10 & $\cdots$ & 7 & $\ldots$ & $2 \frac{1}{3}$ \\
\hline 5 & . & $2 \frac{1}{2}$ & . & 27 & . & 3 \\
\hline $2 \frac{1}{2}$ & $\ldots$ & $3 \frac{1}{2}$ & $\ldots$ & $1 \frac{1}{2}$ & $\ldots$ & 1 \\
\hline $10 \frac{3}{2}$ & $\cdots$ & $11^{\circ}$ & . & $7^{\circ}$ & $\therefore$ & 5 \\
\hline $5 \frac{1}{3}$ & .. & 4 & $\ldots$ & $2 \frac{1}{2}$ & $\ldots$ & 3 \\
\hline $8 \frac{1}{2}$ & . & 2 & $\cdots$ & 1 & . & 0 \\
\hline 2 & .. & 1 & . & 1 & . & 2 \\
\hline $14 \frac{1}{3}$ & .. & 11 & $\ldots$ & 7 & $\ldots$ & 61 \\
\hline 2 & $\cdots$ & 1 & $\therefore$ & 1 & . & 1 \\
\hline 7 & $\cdots$ & 5 & $\cdots$ & 5 b & $\cdots$ & 2 \\
\hline $2 \frac{1}{2}$ & $\cdots$ & 2 & .. & 2 & $\cdots$ & 2 \\
\hline $7 \mathfrak{i}$ & $\cdots$ & 4 & $\cdots$ & $9 \downarrow$ & $\cdots$ & 9t \\
\hline 85 & & 57 & & $41\rfloor$ & & 31 \\
\hline $7 \cdot 0$ & .. & $4 \cdot 7$ & . & $3 \cdot 4$ & . & 3.6 \\
\hline
\end{tabular}

Group B.-Ten Non-readers.

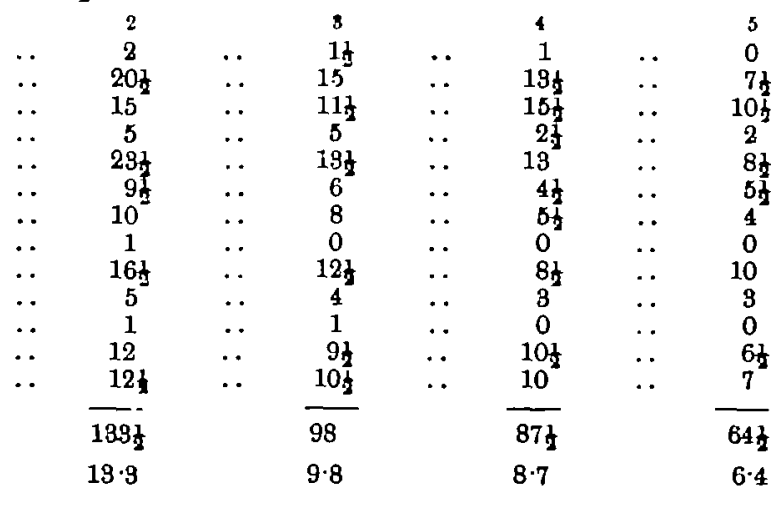


The results were marked as in the preceding experiment. The number of errors on each successive exposure (taking all the digits together) was then found for each group of boys. Finally, the average error per head per exposure was estimated for the two groups.

Table VI gives the actual results.

These results entirely support the inferences made from the preceding experiment, for the inferiority of the non-reading group is evident. It is hard to say, however, how far the comparative failure of this group is due to the difficulty previously noted, their inability to perceive small differences in visual presentations. That this is a difficulty is clear, but that it is the only or even the main difficulty is doubtful. The children's behaviour in this experiment in particular suggested that part of their failure was due, not only to their inability to retain the visual impression, but to the slowness of their association processes, which prevented their getting sufficiently quickly the name of the number presented.

Experiment 7.-To test the subject's ability to recognize words and letters shown under conditions of momentary exposure.

The material used in this experiment consisted of the following words and nonsense words: (1) window ; (2) char ; (3) bok ; (4) floor; (5) feg; (6) tadel; (7) flore; (8) cair; (9) pen; (10) bo ; (11) wall; (12) box; (13) table.

They were printed separately on cards and exhibited in the dropshutter apparatus. Three exposures were made of each word, the subject being required to state what he had seen after each exposure.

Nine readers and ten non-readers performed the experiment. The ten non-readers could, however, recognize under ordinary conditions all the letters and all the words used.

The results were marked on a scheme similar to that used in the preceding experiment. Table VII gives the percentage of error in the two groups:-

TABLE VII.

\begin{tabular}{clllllll} 
& \multicolumn{2}{c}{ No. of exposure : 1 } & & 2 & & 3 \\
Words and & Readers & $\ldots$ & 85 & $\ldots$ & 21 & $\ldots$ & 22 \\
non-words & Non-readers & $\ldots$ & 38 & $\ldots$ & 29 & $\ldots$ & 13 \\
Words alone & Readers & $\ldots$ & 26 & $\ldots$ & 16 & $\ldots$ & 14 \\
& Non-readers & $\ldots$ & 27 & $\ldots$ & 19 & $\ldots$ & 10 \\
Non-words & Readers & $\ldots$ & 59 & $\ldots$ & 34 & $\ldots$ & 30 \\
alone & Non-readers & $\ldots$ & 59 & $\ldots$ & 27 & $\ldots$ & 18
\end{tabular}

Contrary to the results of the preceding experiments, no indication is given here of any difference in ability between the reading and 
non-reading groups. Two reasons may be offered to explain this fact :-

(1) Since the non-reading children had learnt these particular words and letters, they may, for purposes of this experiment, be considered readers. This argument could, however, be equally applied to the work with digits.

(2) It is well known that very little is actually seen under conditions of momentary exposure-what we do see is added to through association and depends very largely on what we expect. This being so, the group of non-readers was at a considerable advantage in this experiment, for they knew only a few words and expected those words to occur in any reading exercise. The readers, on the other hand, had a much wider range of words called up by what they saw, and so were the more liable to error.

It is now possible to summarize certain general inferences that can be made with regard to the power of non-reading children in visual discrimination and learning. Comparing them with readers of equal mental ahility, we find that these children are able:-

(1) To discriminate between unlike forms and to remember them in a normal degree, except in cases in which the forms (a) differ only in part or $(b)$ are alike, except in their orientation.

(2) To make such discriminations equally with the normal, whatever the length of exposure time of the form.

(3) To learn from visual material also in a normal degree when the method of learning is free and the forms easy to distinguish, but

(4) To find sach learning abnormally difficult in cases in which it is (a) more exactly visual and $(b)$ concerned with easily confused material, e.g., digits.

The main reasons suggested as a cause for this trouble are slow discrimination of similar visual presentations and faulty association between a visual impression and its appropriate name. Probably both causes operate in every case.

\section{$\S$ 2.-Experiments to test Auditory Discrimination and Retention.}

Experiment 8. The auditory leaming of digits.-The work of certain of the non-reading subjects had indicated that possibly a specific anditory difficulty existed in some cases of inability to read. The two following experiments were, therefore, planned in order to test the power of the non-reading group as a whole in auditory discrimination and retention. In this first experiment the material used was digits- 
in number and arrangement exactly similar to those used in Experiment 5 , i.e., four 3-place, four 4-place and four 5-place numbers were employed.

The numbers were read by the experimenter at a uniform rate of one digit per second and immediately after the completion of each a reproduction was attempted by the subject.

The results were marked according to the scheme given in Experiment 5 (p. 293). They are recorded below.

Table VIII.-Showing average Error per Boy in the Rephoduction of Digits LEARNT BY HEARING.

\begin{tabular}{|c|c|c|c|c|c|c|c|}
\hline Number of dig & in group : $\mathbf{g}$ & & 4 & & & & Total \\
\hline Readers & . & .. & $0 \cdot 13$ & $\ldots$ & $2 \cdot 6$ & $\ldots$ & $2 \cdot 79$ \\
\hline Non-readers & $0 \cdot 12$ & .. & 0.94 & .. & $4 \cdot 44$ & .. & \\
\hline
\end{tabular}

The non-readers as a gronp have greater difficulty in reproducing digits presented auditorily than do the readers, although their difficulty is not relatively so great as with visual presentation of similar material.

The work with digits was carried out by exactly the same boys in both groups-readers and non-readers.

Experiment 9. The auditory learning of sentences.-The aim of this experiment was to test the power of learning among the nonreaders from auditory material other than digits.

Twenty-four sentences were ased, including four with each of the following number of syllables: $10,11,12,13,14$ and 15 syllables. Each sentence was read aloud to the subject and an immediate reproduction required.

The results were then marked according to the following scheme :-

(1) Insertion or omission of any word $=1$ error.

(2) Misplacement of a word or phrase $=\frac{1}{2}$ error.

The subjects were twenty-three non-readers. The value of the results was estimated by comparison with what is normal for the mental ages of the children concerned.

The actual numerical results (in terms of error) are given in Table IX (page 299).

Most children of from 6 to 7 years of age are able to reproduce accurately sentences of from sixteen to eighteen syllables. Almost all these subjects had a mental age of over 7 years-a fact which indicates that their difficulties in this experiment were far greater than would be expected.

These results, therefore, are in agreement with those of the preceding test-the non-readers as a group show a special disability in retaining and reproducing a series of auditory impressions. 
Table IX.-Showing the Number of Erbors made by bach Subject in the Reproduction OF Sentences.

\begin{tabular}{|c|c|c|c|c|c|c|c|c|c|c|c|c|}
\hline $\begin{array}{l}\text { Number of sylla } \\
\text { in each senten }\end{array}$ & ces & 10 & $\cdots$ & 11 & .. & 12 & . & 13 & .. & 14 & $\cdots$ & 15 \\
\hline $\begin{array}{l}\text { Total number of } \\
\text { lables to be re } \\
\text { duced in grou } \\
\text { four sentences }\end{array}$ & $\begin{array}{l}\text { syl- } \\
\text { pro- } \\
\text { p of }\end{array}$ & 40 & $\cdots$ & 44 & . & 48 & . & 52 & . & 56 & .. & 60 \\
\hline Errors made by & (1) & 3 & . & 2 &. & 15 & $\ldots$ & 7 & . & 7 㱠 & . & 22 \\
\hline & (2) & 0 & $\ldots$ & 0 & .. & 0 & . & 2 & .. & 2 & . & 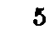 \\
\hline & (3) & 27 & $\cdots$ & 3 & . & 5 & $\ldots$ & 6 & . & 11 & .. & 6 \\
\hline & (4) & 0 & . & 1 & . & 8 & . & 3 & . & 10 & . & 9 \\
\hline & (5) & 0 & . & 2 & $\ldots$ & 2 & $\cdots$ & 2 & $\ldots$ & 7 & . & 10 \\
\hline & (6) & 1, & . & 1 & $\ldots$ & $10\}$ & $\ldots$ & 5 & . & $15 \downarrow$ & . & \\
\hline & (7) & 2 & $\cdots$ & 1 & . & 3 & . & 6 & . & 11 & . & \\
\hline & (8) & 2 & .. & 5 & . & 8 & $\cdots$ & 3 & $\cdots$ & 18 & . & $2 t$ \\
\hline & (9) & 0 & . & 0 & . & 0 & $\cdots$ & 1 & $\ldots$ & 6 & . & \\
\hline & (10) & 0 & $\ldots$ & 0 & $\ldots$ & 0 & $\cdots$ & 4 & $\cdots$ & 0 & . & \\
\hline & (11) & 0 & .. & 0 & $\cdots$ & 0 & $\cdots$ & 0 & $\cdots$ & 1 & . & \\
\hline & (12) & 0 & $\cdots$ & 0 & $\cdots$ & 0 & $\cdots$ & 0 & $\cdots$ & 0 & $\cdots$ & \\
\hline & (13) & 0 & $\cdots$ & 1 & $\cdots$ & 2 & $\cdots$ & 1 & $\cdots$ & $1 \frac{1}{2}$ & $\cdots$ & \\
\hline & (14) & 0 & $\cdots$ & 0 & . & 1 & $\cdots$ & 2 & $\cdots$ & 5 & $\cdots$ & \\
\hline & (15) & 0 & $\ldots$ & 0 & . & 4 & $\cdots$ & 2 & . & 0 & $\cdots$ & \\
\hline & (16) & 0 & . & 0 & $\cdots$ & 0 & $\cdots$ & 0 & $\cdots$ & 0 & . & \\
\hline & (17) & 2 & $\cdots$ & 0 & . & 3 & $\cdots$ & 0 & $\cdots$ & 1 & $\cdots$ & \\
\hline & (18) & $5 \frac{1}{2}$ & $\cdots$ & 8 & $\cdots$ & 14 & $\cdots$ & 14 & $\cdots$ & 19 & $\cdots$ & \\
\hline & (19) & 0 & $\cdots$ & 0 & $\cdots$ & 0 & $\cdots$ & 1 & $\ldots$ & 1 & $\cdots$ & \\
\hline & $(20)$ & 1 & $\cdots$ & 0 & $\cdots$ & 0 & $\cdots$ & 0 & $\cdots$ & $6 \$$ & . & \\
\hline & (21) & 0 & . & 0 & $\cdots$ & 21 & $\cdots$ & 3 & $\cdots$ & 6 & $\cdots$ & \\
\hline & (22) & 0 & $\cdots$ & 0 & $\cdots$ & 0 & $\cdots$ & 0 & $\cdots$ & 1 & . & \\
\hline & (23) & $1 \frac{1}{2}$ & . & 9 & $\ldots$ & 197 & $\ldots$ & 11 & .. & $18\}$ & & \\
\hline
\end{tabular}

Certain points are, however, of special interest:-

(1) Individual differences in capacity revealed by this experiment are very great, much greater than those shown when visual material was used. These differences show no correlation with variations in general mental ability.

(2) Certain subjects whose auditory power as measured by these experiments is very limited, are among the worst readers in spite of the fact that their general mental capacity is comparatively high.

(3) No correlation exists between the findings in the anditory tests and those of certain visual tests, e.g., Experiment 1: correlation between results of Experiments 1 and $8=\cdot 073$, between Experiments 1 and $9=-\cdot 21$.

With regard, then, to the auditory capacity of the non-reading group, we may say :-

(1) That the non-readers as a group show a lowering of anditory power, but that their difficulties in dealing with auditory material are not, on the whole, so great as their difficulties with visual material.

(2) No correlation exists between auditory power as measured by the tests and certain forms of visual power. Defect in either capacity 
seems to be specific rather than an expression of a general lowering of ability.

(3) That certain individuals show anditory difficalties to a peculiarly marked degree. These individuals are especially bad in reading.

§3.-Experiments to test the Power of making Audito-Visual Associations.

We have now to consider the experiments in the final group.

Experiment 10.-The aim of this experiment was to try to estimate the subject's ability to form an association between :-

(a) A given form exhibited visually; and

(b) A common name.

Three sets of forms were prepared-ten in each set-somewhat similar to the forms ased in Experiment 1, except that in this case there were no repeated forms. Corresponding to each set of forms a list of ten common names was made.

The subjects were shown the forms each in tarn for a period of two seconds - the experimenter in the meantime saying, and the subject repeating, the associated name. Immediately after the last form had been shown, the forms were shown again in an order different from that originally used, and the subjects were required to give their associated names. If the sabject failed to give the name after a period of two seconds, it was again given by the experimenter and repeated by the subject. The forms correctly named were put on one side and not given again. This procedure was continued until all the names were known.

Illustrations of the forms are given below.

Series 1. Names: (1) dog; (2) potato; (3) waggon; (4) frog; (5) train; (6) grass; (7) chair; (8) coat; (9) moon; (10) window.

Forms :
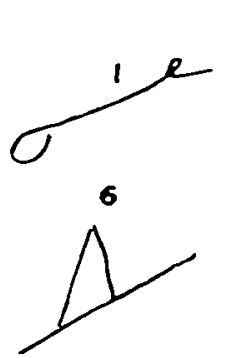
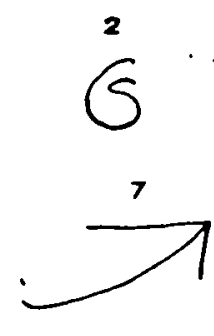
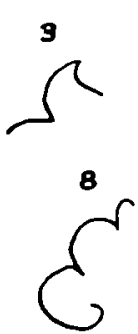

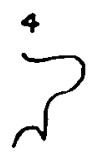

9

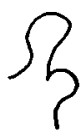

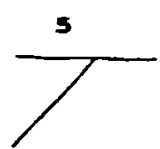

10

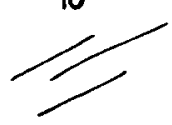


Series 2. Names: (1) shoe; (2) mud; (3) san; (4) boat; rosd ; (6) tree; (7) post; (8) button; (9) sheep ; (10) pond.
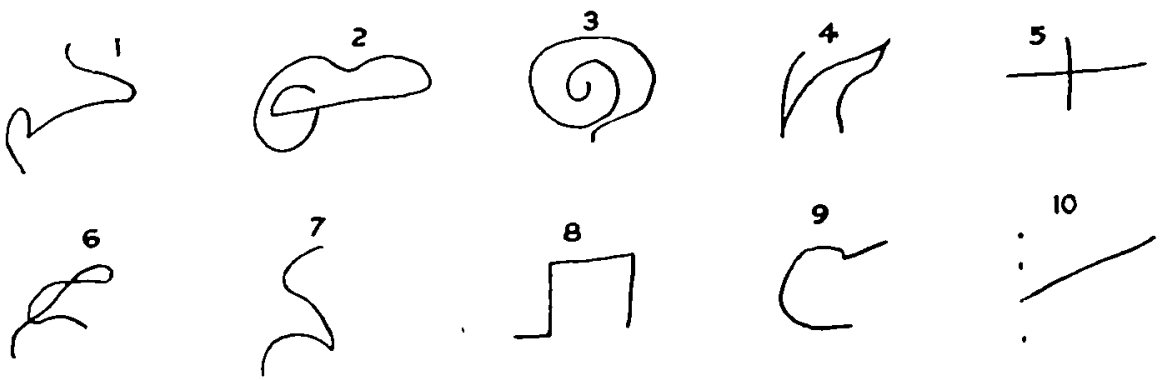

The experiment was carried out by twenty-six readers and thirteen non-readers, and the result is shown in Table $X$.

Table X.-Showtng the Peroentagk of Formb corkeothy nabed at hach Succegsive Exposune, the Results of (a) all the Readers and (b) ale the Non-Readerg being TAKRN TOOETHRE.

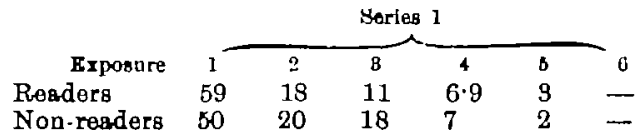

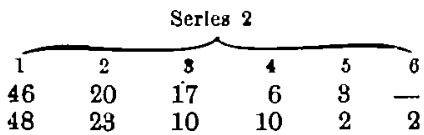

Clearly there is from this experiment no evidence to indicate that the non-readers find association of this type any more difficult than do the readers. Ir fact, two of the worst readers (boys unable to read any words and in one case any letters or fgures) make two of the best scores, whilst the worst score but one is made by a boy who reads fluently.

Certain subsidiary points are important, viz.: (1) There is no evidence to show that the place occupied by the form in the original series has any influence on the ease of recall of the associated name; rather (2) the relative ease of reproduction of the associated name seems determined to a large degree by the nature of the form. This is well shown in Table XI.

\section{Table XI.-Showing the Relation betwhen-}

(a) The nature of the form, and

(b) The number of successes gained on the first attempt at naming. (All the subjects taken together.)

\section{Series 1-}

$\begin{array}{lllllllllllll}\text { Number of form } & \ldots & 1 & 2 & 8 & 4 & 5 & 6 & 7 & 8 & 9 & 10\end{array}$

$\begin{array}{cccccccccccc}\text { Number of successes on } & & & & & & \\ \text { flest naming } & \text { - } & 17 & 27 & 9 & 16 & 27 & 29 & 28 & 22 & 10 & 28\end{array}$

Series 2-

Number of successes on

$\begin{array}{llllllllllll}\text { first naming } & \ldots & 12 & 14 & 18 & 9 & 22 & 7 & 6 & 20 & 12 & 16\end{array}$


The fact that the possibility of remembering the associated name depended, at least in part, on the nature of the form is a particularly interesting one. That it did so depend seems clearly indicated by the results. Forms 7, 10, and 5 of Series 1 , and Forms 5 and 8 of Series 2 could not otherwise have shown to so great an advantage. The names were all ordinary names and it is unlikely that one or two of them should have meant so much more than the rest to a number of children with widely differing environments as to account for the results shown. No child was in the least unfamiliar with any name and the names were remembered almost always when the association was forgotten.

It is difficult to draw any definite conclusions as to what form characteristics rendered naming easy; but it certainly appears as if one important factor was the shape of the forms concerned. A form which could be mentally described by the subjects seemed to be most easily named. Those worst named (Series 1 to 3, Series 2 to 6 and 7) were all of an indefinite shape, not readily to be described in words.

And the accounts of how they remembered given by the subjects lend colour to this view. "There were three lines." "It had dots and a line." "It was round," \&c.

The most successful associations, then, were not simple direct associations between a given visual impression and a given sound. They were associations between a visual impression which had meaning -which was consciously analysed and its parts related definitely to each other - and a sound also full of meaning. For even more often in the records is there indication that the association depended for its retention on the meaning of the word as well as on that of the form, e.g., Series 1 to 2 is said to be remembered " because a potato is round"; Series 2 to 5 " is like a road "- "it is straight"- "it is a cross -cross-roads," while No. 8 of the same series is known "because it's nothing like a button," "a button isn't that shape," \&c.

Suggestive, too, is the behaviour of the subjects. They all enjoyed the experiment and many of them were amused by it. Bat the attitude of any individual in accepting the associated names for the first time differed very considersbly, apparently depending on whether he did or did not consider that the nome fitted the form. To some forms the attitade was one of doubt or question, as if the name had not quite been heard; in the case of others there was a ready acceptance of the name and a look of pleasure. "Button" frequently induced laughter.

This difference, i.e., the fact that the nature of a form, either 
because of its shape or because it fits itself readily on to the associated sound or the meaning of that sound, determines the ease with which the associated sound is retained-is, of course, nothing wore than is generally found with children in learning letters. Therefore, some letters, (e.g., o), are particularly easy while others are hard.

Summarizing the conclusions that can be drawn from these facts it appears:-

(1) That in forming an association between \& visual presentation and a nawe, the elenent of meaning is of primary importance.

(2) That this meaning factor may be inherent in the form itself, or may depend on the nature of the form considered in relation to the meaning involved in the name.

(3) That the less distinctive the forms are in themselves the less easy also is the retention of their associated names; and that therefore

(4) Any difficulty which leads to failure to grasp fully the details of presented forms or to inability to distinguish between them will be likely to render verbal associations with them difficult also.

Experiment 11. The association of words and Greek letters.This experiment aimed at testing the subject's capacity to form associations between common names and letter forms, i.e., it aimed at testing the hypothesis formulated from the results of the last experiment, that the meaning factor inherent in a form is an essential factor in establishing verbal associations with that form.

The material used resembled that used in Experiment 10, except that Greek letters were substituted for the more distinctive forms. The method of procedure was also the same as before.

The letters used were (1) $\gamma$; (2) $\delta$; (3) $\eta$; (4) $\lambda$; (5) $\mu$; (6) $\nu$; (7) $\xi$; (8) $\psi$; and the nomes (1) cow; (2) river; (3) flower; (4) box; (5) wall; (6) paper; (7) rain; (8) hen.

The results show that here the associations were harder to make than in the preceding experiment. In spite of the fact that only eight letters were used as against ten forms, the percentage of successful responses on the second showing of the letters was considerably less than it had been in Experiment 10, i.e., 41 per cent. as against 51 per cent.

The sabjects themselves said that the work was harder because the forms were "like each other." There was a constant tendency to confase "cow," and "box" and "cow" and "peper," owing to the similarity of the forms $\gamma$ and $\lambda$ and $\gamma$ and $\nu$.

It was more difficult in this experiment then in the former to get BRATx.-VOL XHIV. 
any indication from the subjects themselves as to what memory depended on. Usually they declared that they did not know how they remembered. There is, however, some evidence of the influence of meaning. $\gamma$ was said to be "like horns," $\xi$ to "look like rain," \&c.

We find then that the results of this experiment seem to give support to the conclusions previonsly drawn. They show clearly that it is more difficult to form associations between common names and forms which closely resemble each other, not having in themselves any definite characteristics, than between similar names and more distinctive forms.

Experiment 12. Learning the names of eight Greek letters.-An attempt was now made to estimate the subject's power to establish a connection between eight Greek letters and their proper names. The procedure was identical with that of the preceding experiments.

The letters used were $a, \beta, \sigma, \rho, \zeta, \phi, \pi, \theta$.

There is great difficulty in estimating the value of the results in this case, for various reasons, viz. :-

(a) Often the subject was quite unable to say the name after it had been said by the experimenter. Consequently it had to be repeatedsometimes more than once. This fact meant that the time of the original exposure in this experiment was much longer than in the two preceding ones, and a repetition factor, not present with them, was involved.

(b) When the answers (i.e., the associated names) were being given by the subjects, it was often impossible to tell whether the right answer was being given or not. This was particularly so with many of the boys, who conld not, or did not, make correctly such sonnds as "th," \&c.

(c) A considerable tendency to automatism was shown, i.e., one sound (possibly a letter name) was given in answer to all the letters shown. This tendency was due evidently to the felt difficulty of the task. It provides an answer without effort when too great an effort is demanded.

Bearing in mind these facts, with the accompanying result that the children's efforts were judged too leniently, it is interesting to see that here the number of successful responses to the second exhibition of the letters is reduced from 41 per cent. in Experiment 11 to no more than 17 per cent.

A marked difference, also, was shown in the attitude of the subjects. There was little enjoyment. The boys looked worried and baffled, as 
if they were ap against a task which they could not accomplish. It was often hard to retain their attention. The tendency to automatisin has already been noted. Another tendency that was very prevalent was the changing of the name of the letter to one somewhat similar which had meaning to the subject. For example, $\rho$ became "road," $\phi$ became "fine," and $\sigma$ was called "signal." The similarity of many of the names led to great confusion; $\beta, \theta, \zeta$ were continually muddled, all of them being called indiscriminately "beta" or "meta."

It is interesting to note that 44 per cent. of the successes on the second exposure of the letters were with $\pi$, and 32 per cent. with $\beta$, which, as one subject justly remarked, "was like B." No correlation exists between the boys' success in this experiment, and in Experiment $10(\mathrm{r}=0.05)$, but a fairly high correlation is shown between its results and those of the experiment testing the power of immediate reproduction of digits presented auditorily $(r=0.63$; $\mathrm{PE}=0 \cdot 16$ ).

Since, therefore, the only point in which this experiment differed from the preceding one lay in the nature of the name or sound, it is evident that the ease of association between a visual presentation and a sound depends partly on the nature of the sound. The important points with regard to the sound which determine success in reproduction seem to be:-

(a) That it shall have meaning.

(b) That it shall be readily distinguishable.

Summarizing the conclusions that can be drawn from the three allied association experiments, we find :-

(1) That the non-readers as a group make associations between meaningful material (i.e., dissimilar and characteristic forms and words with meaning) as readily as do the readers; but that their difficulty is increased at a rate in excess of that of the readers with the increase in similarity between the forms and sounds presented.

(2) That in all cases the ease with which an association is established between a given form presented visually and a given nams depends on the nature of both name and form, and

(3) That the two points of importance with regard to both form and sound in making for ease of association are: (a) that they shall be readily distinguished from each other; $(b)$ that they shall have meaning, apart from the meaning inherent in their actual presentation.

It is, of course, easy to see that these two points are but one aspect 
of the same thing. The form [ is easier to distinguish from other forms and also to remember than the form $\mathscr{D}$; because by its very nature it has more meaning: "It has three lines and two angles"; "It is two horizontal lines joined by a vertical line on the left"; "It is a square with one side left out" ; "It is nearly a capital $\mathrm{E}$," \&c. In the same way "cow" has more meaning than "beta," although in this case the meaning is not inherent in the form of the word.

Hence cow and [ are more essily retained than and beta. Further, $\Pi$ and button can be associated because $\Pi$ "is not like a button," and $\gamma$ can be associated with cow because " $\mathrm{a}$ cow has horns" ; whereas between 0 and button, and between and beta no links of attachment are likely to occur to the mind.

In the same way, when the figure 6 is known, the letter $b$ may be successfully learnt in spite of years of failare if it is realized that the "bee has six legs."

We see, therefore, that any difficulty which hinders a rapid grasp and differentiation of forms and sounds will be likely to hinder their retention and their association, since the hooks of memory will in such a case be either absent or few in namber.

\section{SUMMARY.}

It is now possible to estimate the bearing of the experimental work which has just been described on the theories commonly held as explanatory of the condition having as its most obvions symptom failure to read or to learn to read. Three points are important.

(1) It is clear from the facts (a) that non-readers are found among all degrees of intelligence; and $(b)$ that the degree of failure in reading, at least among normals and high-grade defectives, shows little correlation with the degree of "general defect" commonly so called, that the defect underlying inability to read is to a certain degree specific in nature. The idea that deficiency in reading power is always an indication of a deficiency of a more general kind is, therefore, by no means supported by the psychological facts; although, of course, the condition known as "general defect" is more frequently accom- 
panied by loss of power in this as in all other abilities than is normal mentality.

(2) Yet there is nothing in the results of the experiments to indicate the existence of any such region as a "visual-word" centre, the absence of or injury to which will make the visual recognition of words impossible. The defects found are not so strictly localized as such a hypothesis would demand, for the word-blind individaals reveal special difficulties in dealing with material other than words. Further, the implication of this theory that ability to read depends on the power to store up images of words has no psychological support; the recall of images is not in question.

(3) The theory that the experiments do support is that "wordblindness" is but one aspect of a more general, yet still in itself specific, defect in either the visual or anditory regions or in both. All the non-readers examined showed a reduction of the normal power in dealing with forms visually presented-especially when these forms were very like each other, their defect being shown most definitely in their failure to remember such forms. Further, certain of the nonreaders showed corresponding defects in the auditory region-they could not readily discriminate or retain similar sounds. Some of the worst cases had defects of both kinds. Taking the group of nonreaders as a whole, however, no correlation could be found between auditory and visual ability, i.e., these defects appeared also to be specific, although occasionally found together in one subject.

Certain of the experiments indicate that the cause of the failure to associate, as well as to retain, sounds and forms, lies to some degree in this primary disability of the auditory or visual regions, resulting as it does in the failure of the forms or sounds presented to gain any meaning. Whether there is also a failure in primary retention, declaring itself in the failure to form memory images to a normal degree, is not known. An inquiry into the use of imagery, depending as it does on the introspection of the subject, is difficult with defective children. Many of them used visual imagery in other matters, but they may, nevertheless, have been unable to visualize forms which had no meaning for them. 